\title{
Dimensions of fluvial-tidal meanders: Are they disproportionally large?
}

\author{
Jasper R.F.W. Leuven*, Barend van Maanen, Bente R. Lexmond, Bram V. van der Hoek, Matthijs J. Spruijt, \\ and Maarten G. Kleinhans \\ Faculty of Geosciences, Utrecht University, Princetonlaan 8A, 3584 CB Utrecht, The Netherlands
}

\begin{abstract}
Many of the world's major river systems seemingly have one or a few disproportionally large meanders, with tight bends, in the fluvial-tidal transition (e.g., the Thames in the UK, and the Salmon River in Canada). However, quantitative studies on meanders have so far primarily focused on rivers without tidal influence or on small tidal meanders without river inflow, providing relations between channel geometry and meander characteristics (length, amplitude, and sinuosity). Physics-based predictions of meander size and shape for the fluvialtidal transition zone remain untested for a lack of data. Therefore, it remains unclear whether the dimensions of meanders in the fluvial-tidal transition zone are indeed disproportionally large, and whether meander characteristics can be used as an indicator for tidal influence. Here, data from 823 meanders in 68 fluvial-tidal transition zones worldwide are presented that reveal broad-brush relations between channel geometry and meander dimensions. Our results show that fluvial-tidal meanders indeed become larger in the seaward direction, but the dimensions are proportional to local channel width, as in rivers. Sinuosity maxima are an exception, rather than the rule, in the fluvial-tidal transition zone. Surprisingly, the width of the upstream river correlates with estuarine channel width and tidal meander size even though river discharge constitutes only a fraction of the tidal prism. The new scaling relations can be used to constrain dimensions of rivers and estuaries and their meanders.
\end{abstract}

\section{INTRODUCTION}

The shapes and dimensions of meanders are a major characteristic of meandering rivers (Leopold and Wolman, 1960). Typical scaling relations exist between meander dimensions, river discharge, and local channel width (e.g., Inglis, 1949; Leopold and Wolman, 1960; Hey and Thorne, 1986) (Table DR1 in the GSA Data Repository $^{1}$ ). However, these empirical relations have never been tested in the fluvial-tidal transition zone and in estuaries (Fig. 1), where one of the signatures of the environment is that local tidal prism (the volume of water leaving an estuary at ebb tide) increases in the seaward direction (Leuven et al., 2018) with exponentially increasing channel width. Observations of tidal meanders show that their planform dimensions scale similarly as in rivers (Marani et al., 2002; Solari et al., 2002; D'Alpaos et al., 2017; Finotello et al., 2018). However, these observations mainly cover meanders on tidal flats and salt marshes, which are much smaller (typically $2-200 \mathrm{~m}$ wide) than fluvial and estuarine meanders. Moreover, they predominantly form under ebb-dominant flow and may thus be comparable with small river meanders (Kleinhans et al., 2009).

The majority of the world's largest cities are located near estuaries and tidal rivers (Ashworth et al., 2015) in which meandering channels are ecologically valuable but also threaten bank stability, affect shipping lanes, and influence flood safety. Therefore, it is of interest whether the meander-forming mechanisms are similar to those of their fluvial counterparts. Physics-based theory can predict dominant meander lengths based on forming mechanisms (e.g., Solari et al., 2002; Schramkowski et al., 2002; Seminara, 2006; for review, see Leuven et al., 2016), but the resulting predictions have never been tested due to a lack of data from natural systems.

Geological outcrops could provide an alternative source of data. However, preserved meandering channel deposits in Palaeozoic outcrops are orders of magnitude smaller than in modern systems (Davies and Gibling, 2011, 2013) and are possibly biased toward maximum meander dimensions and sinuosity, because meanders at the point of cut-off have the highest preservation potential (e.g., Durkin et al., 2017). A possible exception is found in seismic data of the Cretaceous McMurray Formation (Canada), which has kilometer-scale meander bends (Hubbard et al., 2011; Durkin et al., 2017). Both the morphology and the facies in core data are similar to that of a fluvial environment (Mossop and Flach, 1983; Hubbard et al., 2011), although trace fossils indicate brackish water, which is interpreted as the fluvial-tidal transition zone (La Croix and Dashtgard, 2015; Gingras et al., 2016). Therefore, it would be useful to have a complementary indicator that can discriminate between fluvial, fluvial-tidal, and tidal meanders on the basis of geometry for the full range of scales on which they occur on Earth.

Lack of data and empirical generalizations leave hypotheses untested, such as the hypothesis that fluvial-tidal meanders are very tight, with sinuosities peaking above 2.5 at the bedload convergence zone (Dalrymple et al., 2012). The limited number of analyzed cases so far does not demonstrate whether sinuosity peaks significantly beyond the natural temporal and along-channel variability within meandering systems, which occurs due to bend cutoffs, and the scatter in combined observations from multiple systems (Howard and Hemberger, 1991; Camporeale et al., 2007; Hubbard et al., 2011) (Fig. 1B). Moreover, a sinuosity peak implies a disproportional scaling relation between meander dimensions and channel dimensions predicted by theory, because it requires a peak in meander amplitude or drop in meander length.

GSA Data Repository item 2018343, supplementary figures, tables, and a .kml file with the recorded polygons of fluvial-tidal meanders, is available online at http://www.geosociety.org/datarepository/2018/ or on request from editing @ geosociety.org.

*E-mail: j.r.f.w.leuven@uu.nl

CITATION: Leuven, J.R.F.W., van Maanen, B., Lexmond, B.R., van der Hoek, B.V., Spruijt, M.J., and Kleinhans, M.G., 2018, Dimensions of fluvial-tidal meanders: Are they disproportionally large?: Geology, v. 46, p. 923-926, https://doi.org/10.1130/G45144.1. 

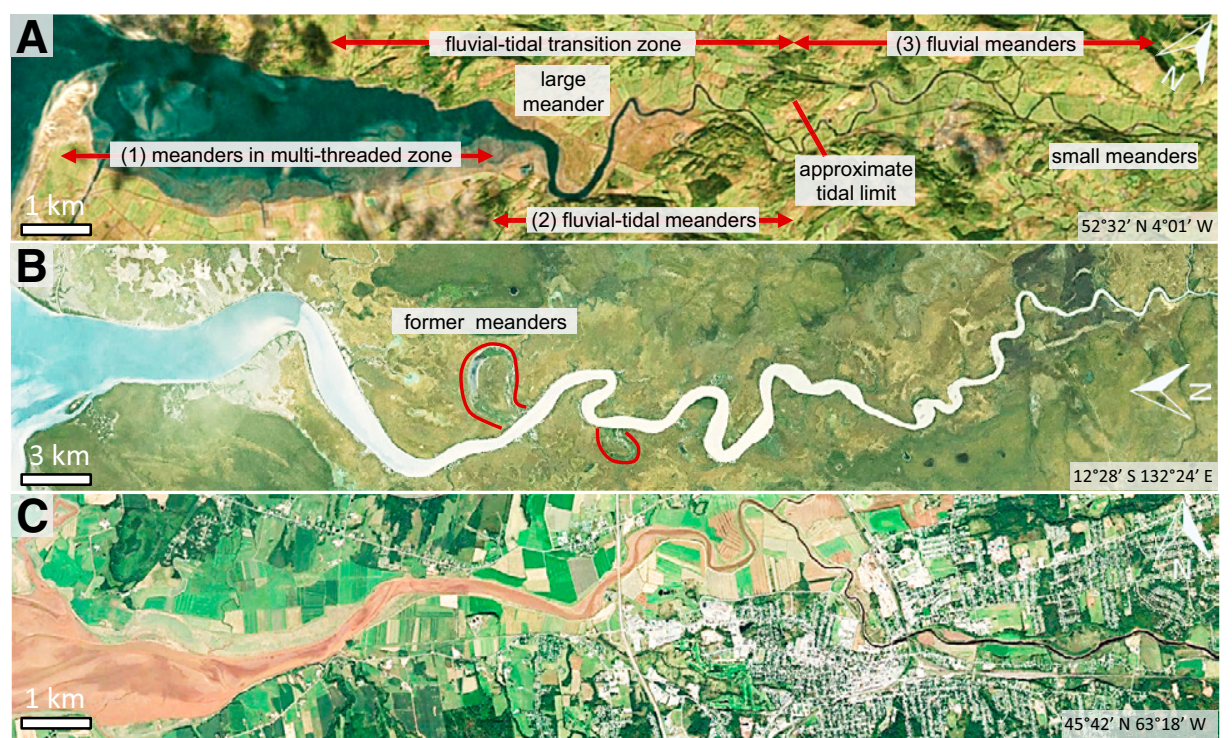

Figure 1. Aerial photographs of fluvial-tidal meanders (Google Earth ${ }^{\mathrm{TM}}$ ). River flow is from right to left. A: Dovey River, Wales, UK. B: South Alligator River, Northern Territory, Australia. C: Salmon River, Cobequid Bay, Canada.
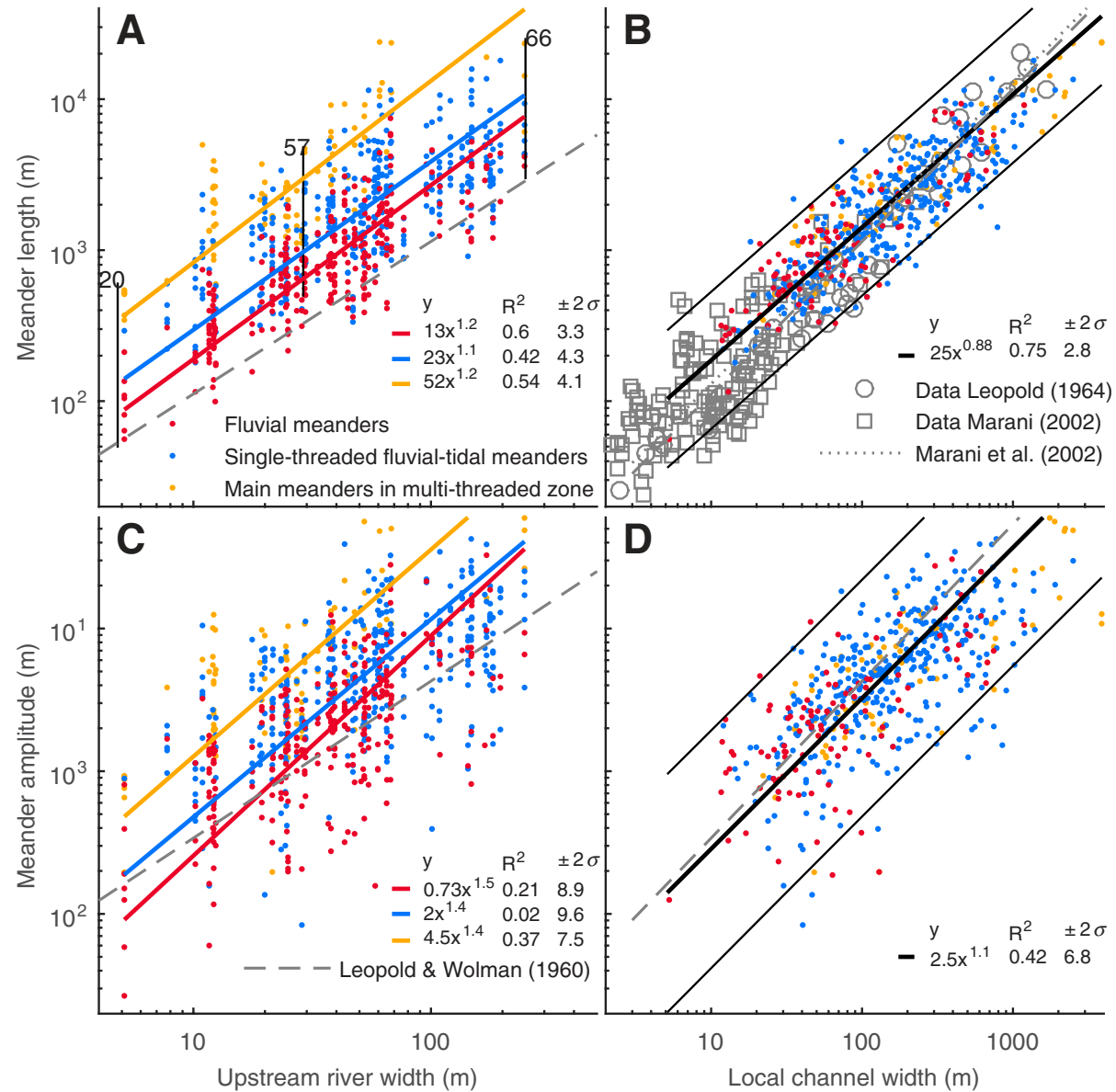

Figure 2. Meander length (A) and amplitude (C) as a function of upstream river width. Vertically aligned symbols indicate along-channel variation per system. Numbers correspond to systems in Table DR2 (see footnote 1). B,D: Dimensions as a function of local channel width, and comparison with fluvial and tidal meanders. Regression in B is based on data from this study only. Confidence limits $(95 \%)$ are indicated by the $2 \sigma$ value.
Observations from aerial photography and predictions from physics-based theory (Solari et al., 2002) suggest that these meanders are longer than those of their fluvial counterparts.

Therefore, we test whether fluvial-tidal meanders are indeed disproportionally large when compared with their local channel dimensions and upstream and downstream meanders. We derive scaling relations that can be used to obtain broad-brush dimensions of meanders along the fluvial-tidal continuum, for application in geomorphology and geological reconstruction of meander belts. To this end, a new data set was collected with characteristics of 823 meanders in 68 fluvial-tidal transition zones from around the world. Data were compared with typical relations previously found for rivers and for small tidal meanders.

\section{DATA COLLECTION AND ANALYSIS}

We recorded channel planform polygons for 68 rivers that transition into seas (Table DR2). Because hydrodynamic data are generally unavailable, the tidal limit was defined as the landward location where channel width approaches a constant value within a factor two of the most upstream river width. Meanders were digitized beyond that point, such that subsequently, the tidal limit could be derived from the along-channel width profile (Figs. DR1 and DR2). To allow for comparison between systems, along-channel distance was normalized with the tidal limit. In cases where the single threaded river transitions into an estuary with braided channels and bars, we digitized the main continuous channel. This approach resulted in a classification of (1) main meanders in the multithreaded zone, (2) single-threaded fluvial-tidal meanders, or (3) fluvial meanders (Fig. 1A).

The channel centerlines and along-channel width profiles were automatically determined using GIS software (following the approaches of Davies and Woodroffe [2010] and Leuven et al. [2018]). All centerlines were smoothed with a Polynomial Approximation with Exponential Kernel (PAEK) algorithm using a tolerance of $0.6 \times$ the local channel width, to prevent the centerlines from being too sensitive to local variations in channel width.

Meander length $(\lambda)$ and amplitude (a) were calculated from the centerlines as follows (Fig. DR3). Inflection points were determined from channel curvature (Howard and Hemberger, 1991; Marani et al., 2002; Schwenk et al., 2015). Meander length was calculated as the Euclidian distance between two successive inflection points with the same sign of curvature (Leopold and Wolman, 1960). Meander amplitude was estimated as the maximum normal distance of channel position from the meander belt centerline determined by the inflection points. Sinuosity was measured as the along-channel distance divided by the Euclidian distance per bend and 
per meander. The channel width for each meander was averaged from digitized channel width. Channel convergence length $\left(L_{\mathrm{w}}\right)$, defined as the distance over which the channel width decreases by a factor $e(\approx 2.72)$, was calculated from a least-squares exponential fit on width as a function of distance. This resulted in a data set with 823 meanders in 68 fluvial-tidal transition zones.

\section{RESULTS AND DISCUSSION}

\section{Meander Dimensions and Characteristics}

Meander length and amplitude generally increase in the seaward direction (Figs. 2A and 2C; Figs. DR4 and DR5). The most landward meanders set the minimum meander dimensions, and are consistent with empirical scaling relations on the basis of river width (Leopold and Wolman, 1960). The most downstream meanders are, on average, approximately $4 \times$ larger than their landward counterparts (as indicated by the regression coefficients) but show an order-of-magnitude variation between systems (Figs. 2A and 2C). Surprisingly, downstream meander dimensions also correlate moderately well to the upstream river width, with a similar power relation.

Meander dimensions scale better with local channel width than with upstream width (Figs. $2 \mathrm{~B}$ and 2D). Given the scatter, the power law is not significantly different from fluvial scaling relations (e.g., Leopold and Wolman, 1960), predictions by stability theory for rivers (Seminara, 2006) (Table DR1), and a relation for small tidal meanders (Marani et al., 2002). The scatter around the trend for meander amplitude is much larger than for meander length, which is at least partly caused by temporal variability due to bend cutoffs, which predominantly reduce meander amplitude but may also affect meander length. These results are consistent with the observed similarity in dimensions and scatter of fluvial and small tidal meanders (Lagasse et al., 2004; Finotello et al., 2018). However, tidal channels show a larger spread of curvature due to the very sharp bends frequently found on tidal flats.
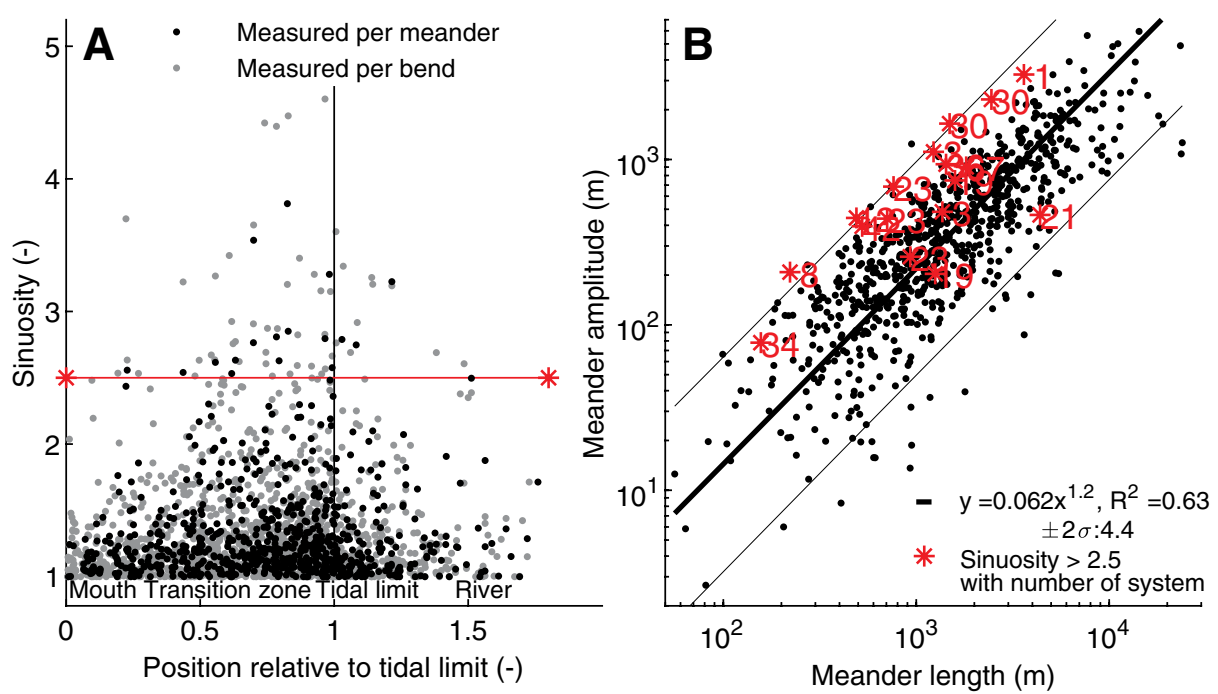

Figure 3. A: Meander sinuosity as a function of position relative to the tidal limit. 11 out of 68 systems have a meander with a sinuosity that peaks above 2.5. B: Meander amplitude versus length. Numbers correspond to systems in Figure DR6 and Table DR2 (see footnote 1).

Case studies suggest that channel sinuosity systematically peaks above 2.5 in the fluvialtidal transition zone (Dalrymple et al., 2012), but in our data set, only 17 of 823 meanders peak above 2.5 (Fig. 3A), which occur in 11 of the 68 systems studied. This shows that sinuosity peaks are an exception rather than the rule for fluvialtidal meanders, which is also consistent with observations of tidal (Finotello et al., 2018) and fluvial meanders (Lagasse et al., 2004). When sinuosity is calculated per bend instead of for the entire meander, 10 additional systems show a peak. However, these sinuosity values above 2.5 are not unique to the fluvial-tidal transition zone, but also occur in the fluvial zone. Meanders with high sinuosities (asterisks in Fig. 3B) are usually caused by large amplitudes, small lengths, or, in some cases, by highly asymmetrical bends (examples are given in Fig. DR6). Meander amplitude correlates well with meander length (Fig. 3B), and the lack of correlation between sinuosity and position (Fig. 3A) shows that meander bends are not disproportionally large in the fluvial-tidal transition.
Scaling Relations for Fluvial-tidal Meanders

While the forcing factors of river discharge and tidal amplitude are entirely independent, a surprising correlation was found between seaward meander dimensions and landward dimensions. As such, a scaling relation is expected between the typical channel convergence length and the proportional change in the amplitude and length of the meanders (Fig. 4A). Convergence length typically scales with tidal range (Savenije, 2006; Davies and Woodroffe, 2010), but our data show the best correlation $\left(\mathrm{R}^{2} \approx 0.7\right)$ between convergence length and upstream riverchannel width (Fig. 4B). In contrast, the correlation between convergence length and most seaward channel width is lower, and convergence length is uncorrelated to tidal range (Figs. $4 \mathrm{C}$ and 4D). Not surprisingly, given the convergencelength relations, the most seaward and upstream channel widths also correlate (Fig. 4E). However, the unexpected implication is that river channel dimensions possibly control estuary dimensions, and the same applies to fluvial-tidal meander dimensions. Channel dimensions (Fig. 4E) and
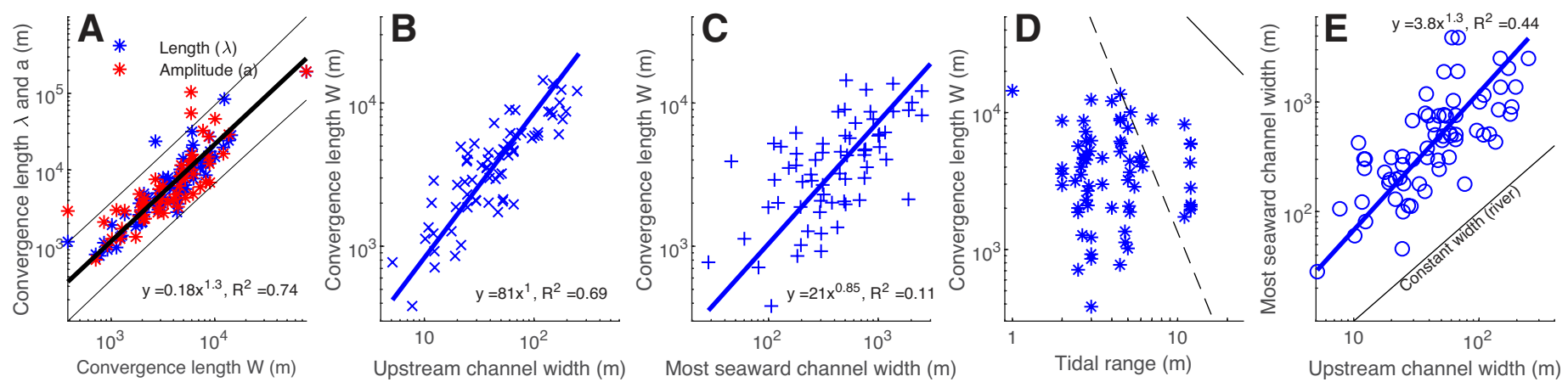

Figure 4. A: Convergence length of meander dimensions (meander length $\lambda$, and amplitude a), defined as the distance over which the dimensions decrease by a factor $e(\approx 2.72)$, as a function of the channel width convergence length. B-D: Channel width convergence length versus upstream channel width (B), seaward channel width (C), and tidal range (D). Two empirical relations between tidal range and convergence (Davies and Woodroffe, 2010) are indicated. E: Most seaward channel width versus upstream channel width. 
meander dimensions (Figs. 2A and 2C) are both, on average, a factor 4 larger at the river mouth.

These results generally indicate a more important fluvial influence than tidal influence on all meander dimensions along the entire fluvial-tidal transition. This is surprising because tidal discharge may exceed fluvial discharge by an order of magnitude (Manning, 2007). Nevertheless, our relations can be used in reconstructions to get a first-order estimation of the channel length of the system, number of point bars occurring in that length, and their approximate dimensions. The upstream river dimensions correlate with the channel convergence length (Fig. 4B). This, in turn, gives an along-channel width profile of the fluvial-tidal transition zone, which can be used to predict an estimate of the meander dimensions that scale with local channel width. In the absence of indications for the location of the mouth, the seaward boundary can be estimated through a combination of the convergence length and the relation between upstream and most-seaward channel width (Fig. 4E).

\section{CONCLUSIONS}

A novel data set demonstrates that meander dimensions in the fluvial-tidal transition zone generally increase in the seaward direction and scale with local channel width, as in river systems, which shows that the meanders are not disproportionally large. The seaward meanders scale with upstream river dimensions, even in multi-channel estuaries where meanders are, on average, $4 \times$ larger. Sinuosity peaks above 2.5 are an exception rather than a rule for fluvial-tidal meanders. Meander characteristics are mainly correlated with the downstream increase of channel width as tidal influence increases. Surprisingly, the characteristic convergence length of channel width is better correlated with the upstream river channel width than with the downstream estuary width and tidal range. In summary, meanders in the transition zone are not excessively large beyond the usual variation and seaward trends.

\section{ACKNOWLEDGMENTS}

This work was funded by the Dutch Technology Foundation Toegepaste en Technische Wetenschappen (grant Vici 016.140.316/13710 to Kleinhans). Paul Durkin and two anonymous reviewers helped to improve the manuscript. Author contributions to conception and design, data collection and processing, analysis and conclusions, and manuscript preparation: JL $(50,50,50,65 \%), \mathrm{BM}(30,10,25,20 \%), \mathrm{BL}$ $(0,15,5,0 \%), \mathrm{BH}(0,15,5,0 \%)$, MS $(0,10,0,0 \%), \mathrm{MK}$ $(20,0,15,15 \%)$.

\section{REFERENCES CITED}

Ashworth, P.J., Best, J.L., and Parsons, D.R., eds., 2015, Fluvial-Tidal Sedimentology: Developments in
Sedimentology, v. 68: New York, Elsevier, 656 p., https://doi.org/10.1016/B978-0-444-63429-7 .00002-X.

Camporeale, C., Perona, P., Porporato, A., and Ridolfi, L., 2007, Hierarchy of models for meandering rivers and related morphodynamic processes: Reviews of Geophysics, v. 45, RG1001, https://doi .org/10.1029/2005RG000185.

D’Alpaos, A., Ghinassi, M., Finotello, A., Brivio, L., Bellucci, L.G., and Marani, M., 2017, Tidal meander migration and dynamics: A case study from the Venice Lagoon: Marine and Petroleum Geology, v. 87, p. 80-90, https://doi.org/10.1016 /j.marpetgeo.2017.04.012.

Dalrymple, R.W., Mackay, D.A., Ichaso, A.A., and Choi, K.S., 2012, Processes, morphodynamics, and facies of tide-dominated estuaries, in Davis, Jr., R.A., and Dalrymple, R.W., eds., Principles of Tidal Sedimentology: Dordrecht, Netherlands, Springer, p. 79-107, https://doi.org/10.1007/978 -94-007-0123-6_5.

Davies, G., and Woodroffe, C.D., 2010, Tidal estuary width convergence: Theory and form in north Australian estuaries: Earth Surface Processes and Landforms, v. 35, p. 737-749, https://doi.org/10 .1002/esp. 1864.

Davies, N.S., and Gibling, M.R., 2011, Evolution of fixed-channel alluvial plains in response to carboniferous vegetation: Nature Geoscience, v. 4, p. 629-633, https://doi.org/10.1038/ngeo 1237.

Davies, N.S., and Gibling, M.R., 2013, The sedimentary record of carboniferous rivers: Continuing influence of land plant evolution on alluvial processes and Palaeozoic ecosystems: Earth-Science Reviews, v. 120, p. 40-79, https://doi.org/10.1016 /j.earscirev.2013.02.004.

Durkin, P.R., Boyd, R.L., Hubbard, S.M., Shultz, A.W., and Blum, M.D., 2017, Three-dimensional reconstruction of meander-belt evolution, Cretaceous McMurray Formation, Alberta Foreland Basin, Canada: Journal of Sedimentary Research, v. 87, p. 1075-1099, https://doi.org/10.2110/jsr.2017.59

Finotello, A., Lanzoni, S., Ghinassi, M., Marani, M., Rinaldo, A., and D'Alpaos, A., 2018, Field migration rates of tidal meanders recapitulate fluvial morphodynamics: Proceedings of the National Academy of Sciences of the United States of America, https://doi.org/10.1073/pnas .1711330115 .

Gingras, M.K., MacEachern, J.A., Dashtgard, S.E., Ranger, M.J., Pemberton, S.G., and Hein, F., 2016, The significance of trace fossils in the McMurray formation, Alberta, Canada: Bulletin of Canadian Petroleum Geology, v. 64, p. 233-250, https://doi.org/10.2113/gscpgbull.64.2.233.

Hey, R.D., and Thorne, C.R., 1986, Stable channels with mobile gravel beds: Journal of Hydraulic Engineering, v. 112, p. 671-689, https://doi.org /10.1061/(ASCE)0733-9429(1986)112:8(671).

Howard, A.D., and Hemberger, A.T., 1991, Multivariate characterization of meandering: Geomorphology, v. 4, p. 161-186, https://doi.org/10.1016 /0169-555X(91)90002-R.

Hubbard, S.M., Smith, D.G., Nielsen, H., Leckie, D.A., Fustic, M., Spencer, R.J., and Bloom, L., 2011, Seismic geomorphology and sedimentology of a tidally influenced river deposit, Lower Cretaceous Athabasca oil sands, Alberta, Canada: The American Association of Petroleum Geologists Bulletin, v. 95, p. 1123-1145, https://doi.org /10.1306/12131010111.
Inglis, C.C., 1949, The Behavior and Control of Rivers and Canals: Poona, India, Central Water-Power Irrigation and Navigation Research Station, v. 13, $486 \mathrm{p}$.

Kleinhans, M.G., Schuurman, F., Bakx, W., and Markies, H., 2009, Meandering channel dynamics in highly cohesive sediment on an intertidal mud flat in the Westerschelde estuary, The Netherlands: Geomorphology, v. 105, p. 261-276, https://doi org/10.1016/j.geomorph.2008.10.005.

La Croix, A.D., and Dashtgard, S.E., 2015, A synthesis of depositional trends in intertidal and upper subtidal sediments across the tidal-fluvial transition in the Fraser River, Canada: Journal of Sedimentary Research, v. 85, p. 683-698, https://doi org/10.2110/jsr.2015.47.

Lagasse, P.F., Zevenbergen, L.W., Spitz, W.J., and Thorne, C.R., 2004, Methodology for Predicting Channel Migration: Washington, D.C., Transportation Research Board, National Cooperative Highway Research Program Project No. 24-16, v. $67,214 \mathrm{p}$.

Leopold, L.B., and Wolman, M.G., 1960, River meanders: Geological Society of America Bulletin, v. 71, p. 769-793, https://doi.org/10.1130/0016 -7606(1960)71[769:RM]2.0.CO;2.

Leuven, J.R.F.W., Kleinhans, M.G., Weisscher, S.A.H., and Van der Vegt, M., 2016, Tidal sand bar dimensions and shapes in estuaries: Earth-Science Reviews, v. 161, p. 204-223, https://doi.org/10 .1016/j.earscirev.2016.08.004.

Leuven, J.R.F.W., Haas, T., Braat, L., and Kleinhans, M.G., 2018, Topographic forcing of tidal sand bar patterns for irregular estuary planforms: Earth Surface Processes and Landforms, v. 43, p. 172 186, https://doi.org/10.1002/esp.4166.

Manning, A.J., 2007, Enhanced UK estuaries database: Explanatory notes and metadata: Wallingford, UK, HR Wallingford Technical Report TR167.

Marani, M., Lanzoni, S., Zandolin, D., Seminara, G., and Rinaldo, A., 2002, Tidal meanders: Water Resources Research, v. 38, p. 7-1-7-14, https:// doi.org/10.1029/2001WR000404

Mossop, G.D., and Flach, P.D., 1983, Deep channel sedimentation in the Lower Cretaceous McMurray formation, Athabasca Oil Sands, Alberta: Sedimentology, v. 30, p. 493-509, https://doi.org /10.1111/j.1365-3091.1983.tb00688.x.

Savenije, H.H., 2006, Salinity and tides in alluvial estuaries: Amsterdam, Netherlands, Elsevier, 208 p.

Schramkowski, G., Schuttelaars, H., and De Swart, H., 2002, The effect of geometry and bottom friction on local bed forms in a tidal embayment: Continental Shelf Research, v. 22, p. 1821-1833, https://doi.org/10.1016/S0278-4343(02)00040-7.

Schwenk, J., Lanzoni, S., and Foufoula-Georgiou, E., 2015, The life of a meander bend: Connecting shape and dynamics via analysis of a numerical model: Journal of Geophysical Research: Earth Surface, v. 120, p. 690-710, https://doi.org/10 1002/2014JF003252.

Seminara, G., 2006, Meanders: Journal of Fluid Mechanics, v. 554, p. 271-279, https://doi.org/10 1017/S0022112006008925.

Solari, L., Seminara, G., Lanzoni, S., Marani, M., and Rinaldo, A., 2002, Sand bars in tidal channels: Part 2. Tidal meanders: Journal of Fluid Mechanics, v. 451, p. 203-238, https://doi.org/10.1017 /S0022112001006565.

Printed in USA 